\title{
Suppression of Structural Fatigue by Doping in Spinel Electrode Probed by In Situ Bending Beam Method
}

\author{
Kyung Yoon Chung, ${ }^{\mathrm{a}, \mathrm{b}, *}$ Won-Sub Yoon, ${ }^{\mathrm{c}, * *}$ Kwang-Bum Kim, ${ }^{\mathrm{a}, \mathrm{d}, \mathrm{z}}$ \\ Xiao-Qing Yang, ${ }^{\mathrm{c}, * *}$ and Seung Mo $\mathrm{Oh}^{\mathrm{d}}, * *$ \\ ${ }^{a}$ Department of Metallurgical Engineering, ${ }^{b}$ Yonsei Center for Nano Technology, Yonsei University, \\ Seoul 120-749, Korea \\ ${ }^{c}$ Brookhaven National Laboratory, Materials Science Department, Upton, New York 11973, USA \\ ${ }^{d}$ Research Center for Energy Conversion and Storage, Seoul 151-744, Korea
}

\begin{abstract}
The onset of a Jahn-Teller effect at the surface of $\mathrm{LiMn}_{2} \mathrm{O}_{4}$ particles during cycling in the $4 \mathrm{~V}$ range was previously reported to be one of the causes for the capacity fading. Furthermore, it has been reported that the Jahn-Teller effect in the $4 \mathrm{~V}$ range may be suppressed by the substitution of the Mn ions by either Li or other transition metal ions. However, no direct evidence has yet been reported. This study provides evidence for the onset of a Jahn-Teller effect in thin film $4 \mathrm{~V} \mathrm{LiMn}_{2} \mathrm{O}_{4}$ and its suppression caused by substituting the $\mathrm{Mn}$ ions with $\mathrm{Co}^{3+}$ and $\mathrm{Ni}^{2+}$ ions using in situ bending beam method (BBM). The deflectograms are measured simultaneously with galvanostatic charge/discharge or cyclic voltammograms, and the onset of the Jahn-Teller effect is investigated by means of the differential strain peak which is observed at around 3.90-3.95 V during cyclic voltammetry, and the slope variation observed in the strain curves during galvanostatic charge/discharge. The suppression of the Jahn-Teller effect in the doped spinel leads to the magnitude of the differential strain peak resulting from the Jahn-Teller effect being reduced in comparison with the other two pairs of peaks, which correspond to the current peaks of the cyclic voltammogram. (C) 2004 The Electrochemical Society. [DOI: 10.1149/1.1646146] All rights reserved.
\end{abstract}

Manuscript submitted October 7, 2002; revised manuscript received April 25, 2003. Available electronically February 11, 2004.

There has been rapid progress in the portable electronics industry, and this has led to an enormous increase in the demand for portable, lightweight power sources, and it is lithium secondary batteries that have satisfied this demand. The possible candidates for the cathode material for lithium secondary batteries are $\mathrm{LiCoO}_{2},{ }^{1-4}$ $\mathrm{LiNiO}_{2},{ }^{5-8}$ and $\mathrm{LiMn}_{2} \mathrm{O}_{4},{ }^{9}$ and there have been extensive studies performed on these materials. At present, $\mathrm{LiCoO}_{2}$ is widely used, but $\mathrm{LiMn}_{2} \mathrm{O}_{4}$ is an excellent alternative material in view of its advantages, such as low cost, environmental benignity, and the ready availability of its associated raw materials. However, $\mathrm{LiMn}_{2} \mathrm{O}_{4}$ has a disadvantage which involves capacity fading during cycling. Many explanations have been given as to why the capacity might fade in the $4 \mathrm{~V}$ range, such as $\mathrm{Mn}$ dissolution into electrolyte, ${ }^{10}$ structural instability in the high voltage region, ${ }^{11}$ etc. One of these explanations is the onset of a Jahn-Teller effect at the end of discharge. Thackeray et al. reported the onset of a Jahn-Teller effect at the end of discharge in the $4 \mathrm{~V}$ range in their study using transmission electron microscopy (TEM), which is an ex situ technique. ${ }^{12-16}$ Also, we previously reported evidence of the onset of a Jahn-Teller effect in the $4 \mathrm{~V}$ range during cyclic voltammetry, using the in situ bending beam method (BBM). ${ }^{17}$ Under dynamic, nonequilibrium conditions during discharging, some crystallites are more lithiated than others, thereby driving the composition of the electrode surface into a $\mathrm{Mn}^{3+}$-rich region. This induces a Jahn-Teller effect and transforms the surface of the $\mathrm{LiMn}_{2} \mathrm{O}_{4}$ particles from cubic to tetragonal phase. As the lattice parameter of the tetragonal phase differs from that of the cubic phase, there is a misfit between the phases and some of the tetragonal phase may dissociate from the bulk electrode. In the previous report by Lim et al., cracks at the surface of the spinel particles after cycling were observed by scanning electron microscopy (SEM), and this may be attributed to the above effect. ${ }^{18}$ This leads to the loss of electroactive species and of electronic contact, thus turning this part into electrochemically dead volume, and this contributes to the capacity fading. ${ }^{13,14,17}$

There has been an earlier report by other authors suggesting that the capacity fading due to a Jahn-Teller effect in the $4 \mathrm{~V}$ range may be suppressed by the substitution of the Mn ions with lithium ions or other transition metal ions..$^{12,13,15}$ The authors of this report prepared

\footnotetext{
* Electrochemical Society Student Member.

** Electrochemical Society Active Member.

z E-mail: kbkim@yonsei.ac.kr
}

doped spinel oxides of several compositions, and compared the cycleability characteristics with stoichiometric spinel oxide (i.e., $\mathrm{LiMn}_{2} \mathrm{O}_{4}$ ). The doped spinel oxide showed better cycleability than the stoichiometric spinel oxide. The authors attributed this improvement to the suppression of the Jahn-Teller effect in the spinel electrode at the end of discharge in the $4 \mathrm{~V}$ range. However, they were not able to produce any direct evidence that this improvement could really be attributed to the suppression of the Jahn-Teller effect in the $4 \mathrm{~V}$ range, and they also mentioned that these doped spinel oxides suppress the dissolution of the Mn ions into the electrolyte. Therefore, to evaluate whether the doping of these spinel oxides contributes to the suppression of the Jahn-Teller effect and their cycleability, more detailed studies need to be done in order to produce direct evidence of this effect.

In this study, direct evidence of the onset of a Jahn-Teller effect at the end of discharge during galvanostatic charge/discharge and cathodic scan during cyclic voltammetry in the $4 \mathrm{~V}$ range and the suppression of a Jahn-Teller effect by substitution of the Mn ions with other transition metal ions $\left(\mathrm{Co}^{3+}, \mathrm{Ni}^{2+}\right)$ is obtained by means of the in situ BBM. By substituting the Mn ions with other metal ions which have a lower valence than the Mn ions, the average oxidation state of the Mn ions is increased and this increased oxidation state acts as a cubic buffer zone that suppresses the onset of the Jahn-Teller effect. ${ }^{12,13,15}$ Therefore, the Jahn-Teller effect is suppressed, and the cycleability of the spinel oxide is enhanced at the expense of initial capacity. The improvement in the cycleability resulting from doping can be attributed for the most part to the suppression of the Jahn-Teller effect. However, we cannot exclude the possibility of other factors being involved in the observed improvement resulting from doping.

\section{Experimental}

The synthesis of the $\mathrm{LiM}_{\delta} \mathrm{Mn}_{2-\delta} \mathrm{O}_{4}(\mathrm{M}=\mathrm{Co}$ and $\mathrm{Ni} ; \delta=0$, 0.05 , and 0.1 ) thin film electrodes was carried out by means of the electrostatic spraying deposition (ESD) technique. ${ }^{17,19-26}$ The precursor solution consisted of very dilute ethanolic solution of $\mathrm{CH}_{3} \mathrm{CO}_{2} \mathrm{Li} \cdot 2 \mathrm{H}_{2} \mathrm{O}, \quad \mathrm{Mn}\left(\mathrm{NO}_{3}\right)_{2} \cdot 4 \mathrm{H}_{2} \mathrm{O}, \quad \mathrm{Co}\left(\mathrm{NO}_{3}\right)_{2} \cdot 6 \mathrm{H}_{2} \mathrm{O}, \quad$ and $\left(\mathrm{CH}_{3} \mathrm{CO}_{2}\right) \mathrm{Ni} \cdot 4 \mathrm{H}_{2} \mathrm{O}$ in a stoichiometric molar ratio. In this study, a thin glass plate coated with platinum on one side was used as a substrate. The platinum-coated side works as a current collector and the opposite side works as a mirror, by means of which the laser beam is reflected. The needle to substrate distance was set to 2 $\sim 4 \mathrm{~cm}$. The applied voltage between the needle and the substrate 


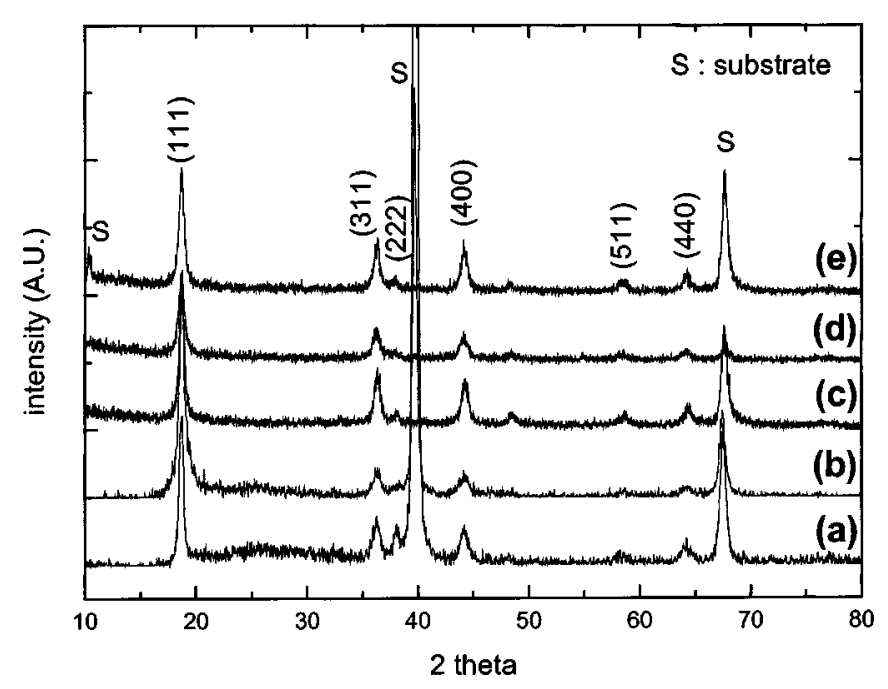

Figure 1. XRD pattern of thin film $\mathrm{LiM}_{\delta} \mathrm{Mn}_{2-\delta} \mathrm{O}_{4}$ deposited at $300^{\circ} \mathrm{C}$ and annealed at $400^{\circ} \mathrm{C}$ for $2 \mathrm{~h}$. (a) $\mathrm{LiMn}_{2} \mathrm{O}_{4}$, (b) $\mathrm{LiCo}_{0.05} \mathrm{Mn}_{1.95} \mathrm{O}_{4}$, (c) $\mathrm{LiCo}_{0.1} \mathrm{Mn}_{1.9} \mathrm{O}_{4}$, (d) $\mathrm{LiNi}_{0.05} \mathrm{Mn}_{1.95} \mathrm{O}_{4}$, and (e) $\mathrm{LiNi}_{0.1} \mathrm{Mn}_{1.9} \mathrm{O}_{4}$

was $12 \mathrm{kV}$, and the surface temperature was set at $200-300^{\circ} \mathrm{C}$ during deposition. The flow rate of the precursor solution was fixed at 2 $\mathrm{mL} / \mathrm{h}$, and a total of $2 \mathrm{~mL}$ was sprayed. The dimension of the deposited area was $2 \times 10 \mathrm{~mm}$. After deposition, the samples were annealed at 300 to $800^{\circ} \mathrm{C}$ for $2 \mathrm{~h}$ and left to cool in the furnace.

To measure the strain, we used the BBM, which was originally invented by Stoney. ${ }^{27}$ After Stoney invented this technique, various modifications and improvements in the experimental setup and analytical methods have been made by many researchers. ${ }^{28-30}$ These researchers overcame the problems associated with the elastic modulus in the multilayer structure by using a modified formula involving the use of the $E_{\mathrm{s}}$ (elastic modulus of substrate) and $E_{\mathrm{c}}$ (elastic modulus of coating) in their analysis. In the present study, we adopted the use of an improved experimental setup based on improvement made to Stoney's setup by Rosolen et al. ${ }^{28}$ and measured the strain generated during the electrochemical reactions. The schematic diagram of our experimental setup is shown and explained in detail in our previous report. ${ }^{17}$ In the BBM system, a $\mathrm{He}-\mathrm{Ne}$ laser beam is reflected from the glass side of the electrode. Since the glass substrate is coated with platinum, the platinumcoated side works as a current collector and the reverse side works as a mirror. The position detector was used to detect the deflection of the reflected laser beam caused by the bending of the working electrode. The in situ strain measurements of the electrodes in this study were carried out during cyclic voltammetry. The dimensions of the substrate were $60 \mathrm{~mm}$ (length) $\times 2 \mathrm{~mm}$ (width) $\times 0.13 \mathrm{~mm}$ (thickness). Because the substrate used was very thin, the deflection of the laser beam, which is caused by the bending of the substrate, is very sensitive to the strain of the cathode materials, and this could be measured simultaneously with the measurement of the electrochemical signals.

The electrochemical cell used in this study was a beaker cell made of Teflon with three electrodes fixed on the plastic cap that hermetically closed the cell. The cell has an optical glass window behind the working electrode to allow the laser beam to pass through. The counter and reference electrodes were lithium metal foil, and the electrolyte used was $1 \mathrm{M} \mathrm{LiClO}_{4} / \mathrm{PC}$. The assembling and sealing of the cell were carried out in a glove box under a dry argon atmosphere.

\section{Results and Discussion}

The XRD patterns of $\mathrm{LiM}_{\delta} \mathrm{Mn}_{2-\delta} \mathrm{O}_{4}(\mathrm{M}=\mathrm{Co}$ and $\mathrm{Ni} ; \delta=0$, 0.05 , and 0.1 ) synthesized by the ESD technique are shown in Fig. 1. The peaks marked $\mathrm{S}$ are from the substrate. All the XRD patterns could be indexed to the cubic spinel of space group $F d 3 m$. No sign of the tetragonal phase was observed. Using the ESD technique, we were able to obtain single-phase $\mathrm{LiM}_{\delta} \mathrm{Mn}_{2-\delta} \mathrm{O}_{4}$ thin film electrodes without any additives, and this means that the measured strain or electrochemical response is exclusively due to the cathode material itself.

There are two modes involved in the strain observed in an electrode coated with electroactive materials, tensile strain and compressive strain, as represented in Fig. 2. There are several causes for the strain inherent in electrodes, and these are explained in our previous report. ${ }^{17}$ In the present study, the measured strain is due to two major factors, which are the volume variation of the electroactive material due to lattice parameter change, and the phase transformation during lithium insertion/extraction. The effect of other factors can be disregarded on the basis of electrochemical quartz crystal microbalance (EQCM) data obtained in our laboratory and the reason for this is explained elsewhere. ${ }^{17}$ When the lithium ions are inserted/extracted into/out of the spinel matrix, an accompanying lattice parameter change takes place, i.e., volume change. Also, phase transformation between the cubic and tetragonal phases involves change in the lattice parameters, but this is a rather abrupt change compared with the gradual change caused by the lithium ion insertion/extraction. ${ }^{31}$ There is compressive strain when the volume of the electroactive material increases and tensile strain when it decreases.

In the strain measurement, the morphology and the adherence of the electroactive material to the substrate is very important. If the morphology of the cathode material film were porous and the adhesion of the film to the substrate were poor, the strain of the film would not be totally exerted on the substrate, and the precise measurement of the strain would not be possible. Therefore, in investigating the strain of the cathode material, the preparation of a dense film with good adhesion is an essential factor. Figure 3 shows SEM images of the thin-film spinel oxide before electrochemical cycling with both surface and cross-sectional views. From Fig. 3a, it can be seen that a dense film of spinel oxide is present on the substrate. The cross-sectional image in Fig. $3 \mathrm{~b}$ shows that the adhesion of this film to the substrate is very good.

To demonstrate the validity of the strain measurement during the experiment, we investigated the change in the morphology and the adhesion of the spinel oxide to the substrate after cycling. Figure 4 shows the surface and cross-sectional SEM images of the thin-film spinel oxide after cycling twice with cyclic voltammetry. The cutoff voltages were 3.5 and $4.35 \mathrm{~V}$, and the scan rate was $0.1 \mathrm{mV} / \mathrm{s}$. Even after cycling twice, the morphology of the thin film $\mathrm{LiMn}_{2} \mathrm{O}_{4}$ electrode in Fig. 4a does not appear to show any difference from that of Fig. 3a. Also, the cross-sectional image in Fig. 4b still shows good adherence of the spinel oxide film to the substrate. Based on these

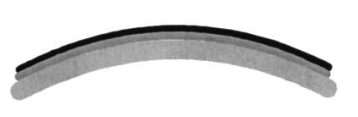

(a) compressive strain

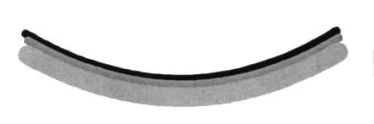

(b) tensile strain

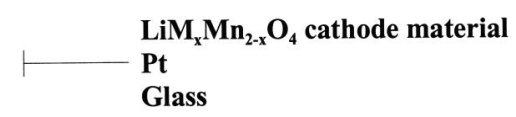

Glass

Figure 2. Two modes of strain observed in an electrode coated with thin film $\mathrm{LiM}_{\delta} \mathrm{Mn}_{2-\delta} \mathrm{O}_{4}$ : (a) compressive strain-volume expansion and (b) tensile strain-volume contraction. 


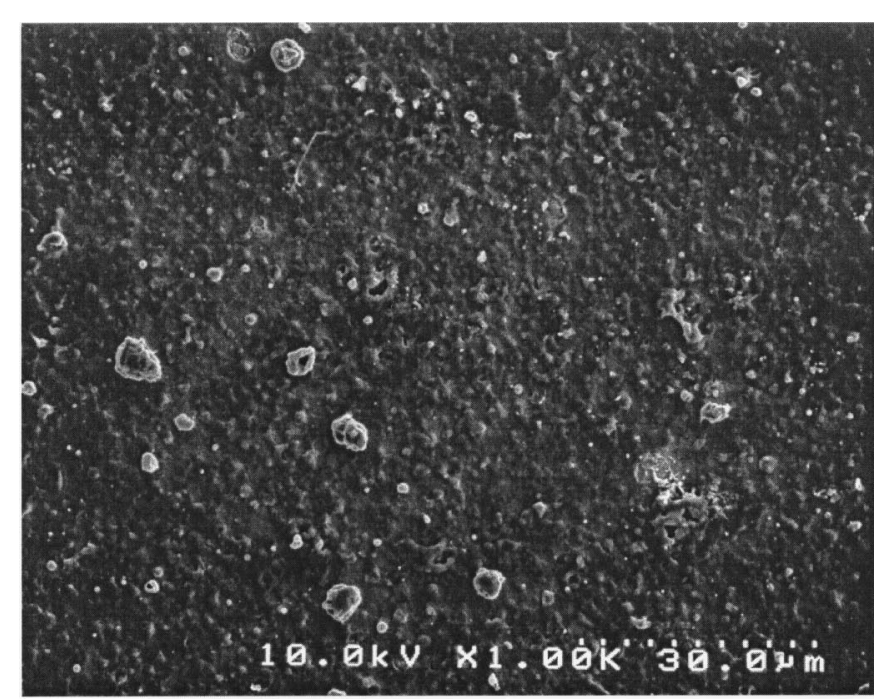

(a)

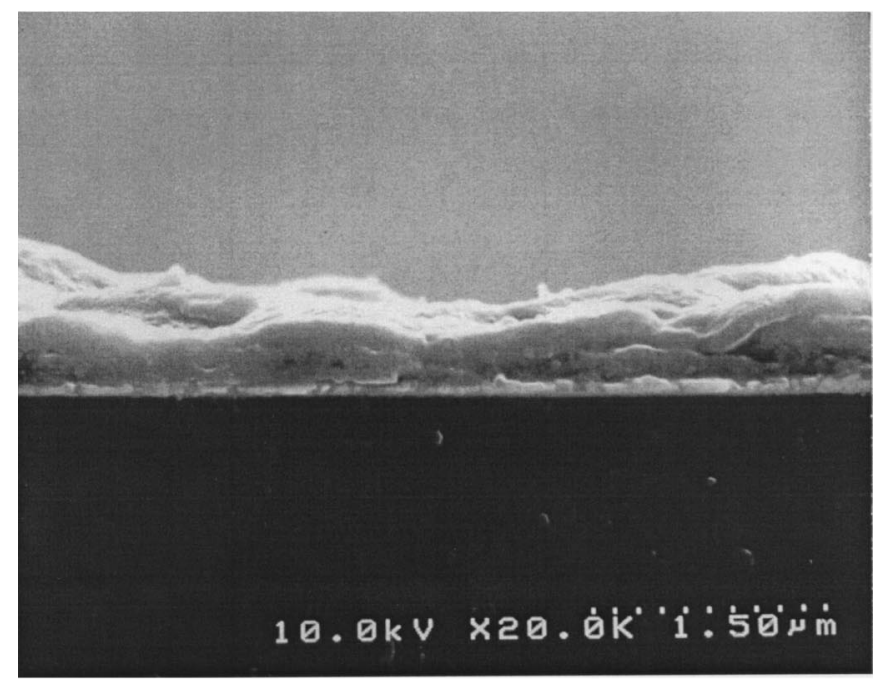

(b)

Figure 3. SEM images of thin-film $\mathrm{LiMn}_{2} \mathrm{O}_{4}$ electrode before electrochemical cycling: (a) film surface, (b) cross section of the film.

images, the validity of the strain measured using BBM can be confirmed.

It has been previously reported that a Jahn-Teller effect takes place when the average oxidation state of the Mn ions becomes less than 3.5. ${ }^{32}$ The initial average oxidation state of stoichiometric $\mathrm{LiMn}_{2} \mathrm{O}_{4}$ is 3.5 and that of $\mathrm{Li}_{1-x} \mathrm{Mn}_{2} \mathrm{O}_{4}$ increases as the $x$ value increases, and theoretically the average oxidation state of the Mn ions in the fully charged state of spinel oxide should be $4+$. When the stoichiometric spinel oxide is fully discharged, the average oxidation state of the Mn ions should be 3.5, and there should not be a Jahn-Teller effect. However, according to Thackeray et al. at nonequilibrium dynamic conditions, due to the accumulation of lithium ions at the surface of the spinel oxide, the average oxidation state of the Mn ions at the surface of the spinel particles falls below 3.5, and a Jahn-Teller distortion takes place. ${ }^{12-16}$ They observed the formation of a tetragonal phase in the spinel electrodes, which are discharged to $3.0,3.3$, and $3.5 \mathrm{~V}$, respectively. This reveals that the onset of the Jahn-Teller effect takes place at above $3.5 \mathrm{~V}$. However, if the average oxidation state of the $\mathrm{Mn}$ ions of the spinel oxide in the fully discharged state could become slightly greater than 3.5, even for the lithium ions accumulated at the surface of the spinel oxide particles, the onset of the Jahn-Teller effect would be sup-

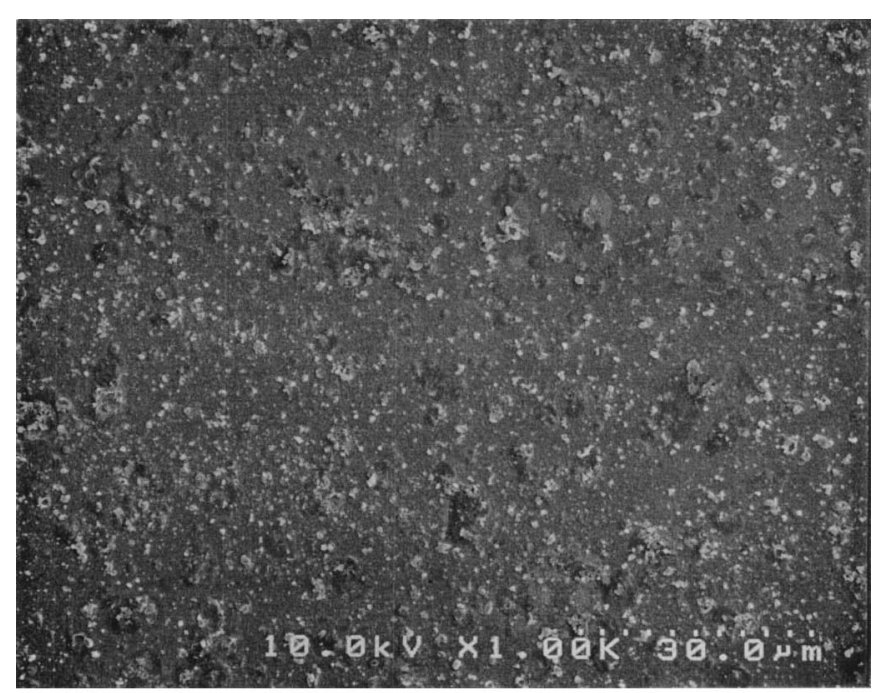

(a)

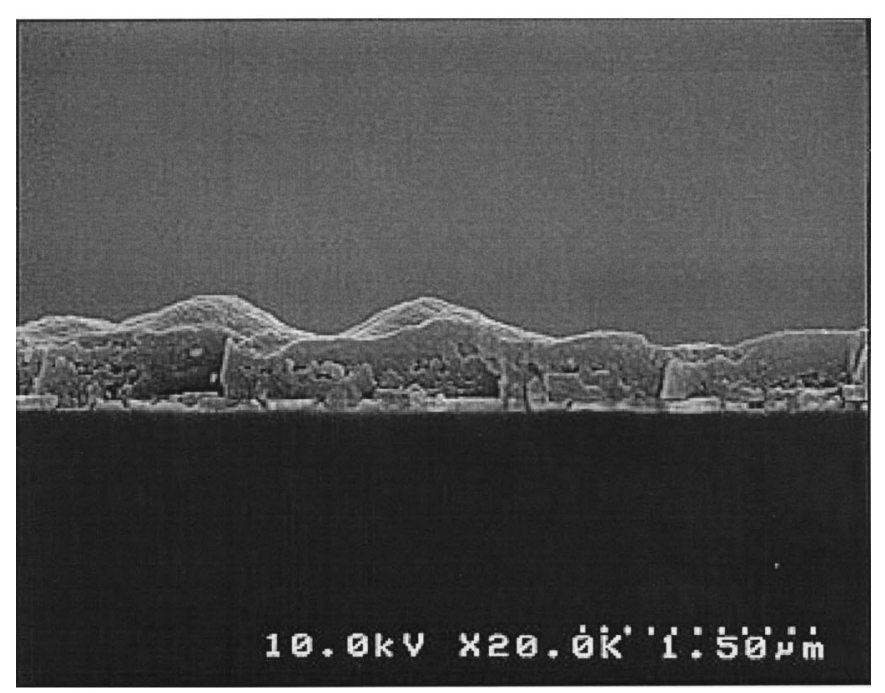

(b)

Figure 4. SEM images of thin-film $\mathrm{LiMn}_{2} \mathrm{O}_{4}$ electrode cycled twice with cyclic voltammetry. Cutoff voltage: $3.5-4.35 \mathrm{~V}$, scan rate: $0.1 \mathrm{mV} / \mathrm{s}$. (a) Film surface, (b) cross section of the film.

pressed, and this would lead to an improvement in the cycleability. This hypothesis was previously reported by Thackeray et al., who suggested that by substituting the Mn ions with lithium ion or other transition metal ions, the Jahn-Teller effect might be suppressed. ${ }^{12,14,15}$ However, to the best of our knowledge, no direct evidence for the suppression of the Jahn-Teller effect in the $4 \mathrm{~V}$ range has yet been reported. In the present study, we provide direct evidence for the onset and suppression of the Jahn-Teller effect in the $4 \mathrm{~V}$ range of a $\mathrm{LiM}_{\delta} \mathrm{Mn}_{2-\delta} \mathrm{O}_{4}(\mathrm{M}=\mathrm{Co}$ and $\mathrm{Ni} ; \delta=0,0.05$, and 0.1) electrode, which was obtained using the in situ BBM.

Figure 5 shows the strain and differential strain curves of the second cycle, superimposed on the galvanostatic charge/discharge curves of the thin film $\mathrm{LiMn}_{2} \mathrm{O}_{4}$ electrode. The strain curve in Fig. $5 \mathrm{a}$ can be divided into three regions, which are designated as A- $\mathrm{A}^{\prime}$, $\mathrm{B}-\mathrm{B}^{\prime}$, and $\mathrm{C}-\mathrm{C}^{\prime}$. Region $\mathrm{B}-\mathrm{B}^{\prime}$ shows the gentlest slope, and region A- $\mathrm{A}^{\prime}$ shows the steepest slope. In a similar manner to the galvanostatic charge/discharge curve, the strain curve shows a slight hysteresis between the strain curves of charge and discharge. These slope variations can be observed more clearly in the differential strain curve. In Fig. 5b, the differential strain curve is shown, and it can be 

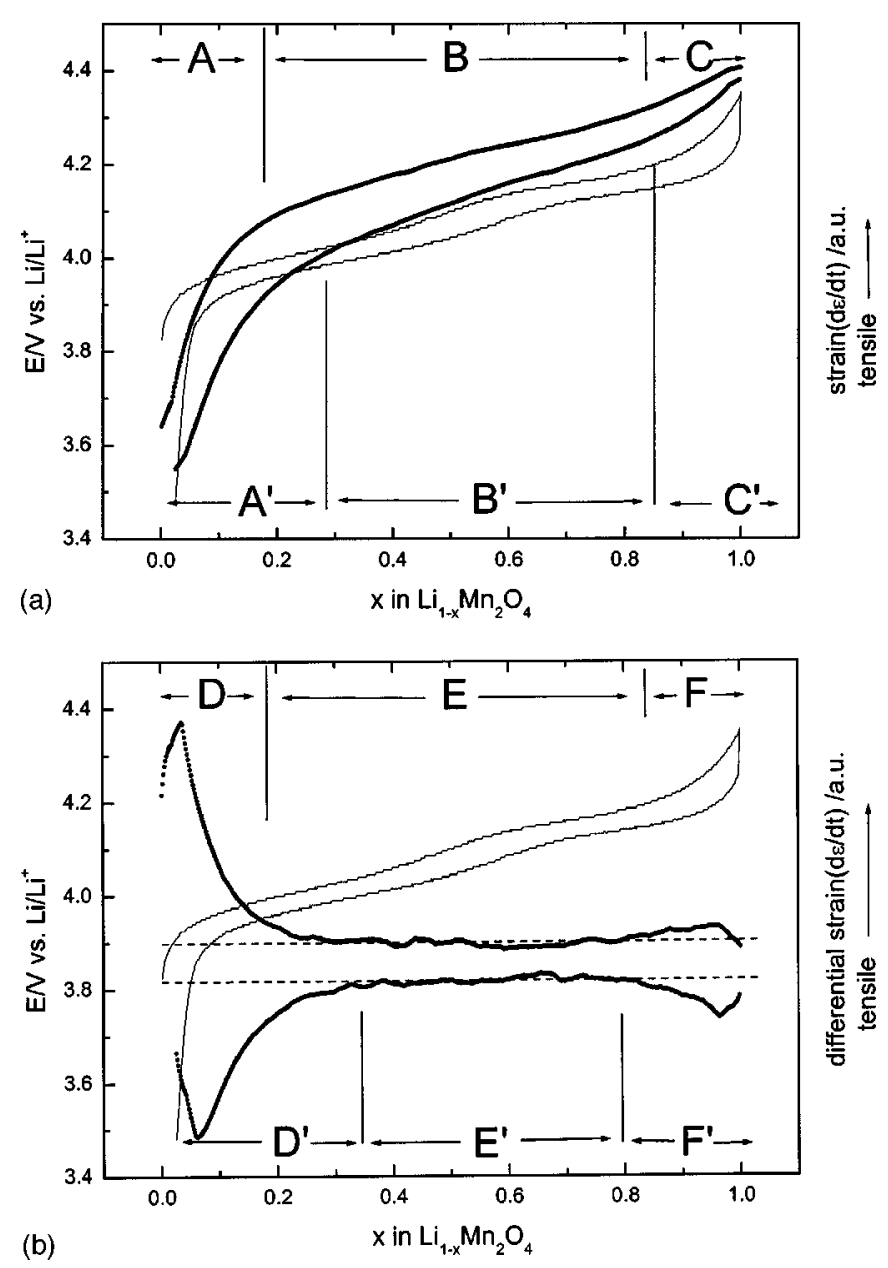

Figure 5. (a) Strain curves (thick line) and (b) differential strain curves (thick line) superimposed on the galvanostatic charge/discharge curves of thin film $\mathrm{LiMn}_{2} \mathrm{O}_{4}$. Applied current: $20 \mu \mathrm{A}$, cutoff voltage: $3.5-4.35 \mathrm{~V}$. The dashed lines in (b) are the reference lines.

divided into three regions as in the case of the strain curve, and these regions are designated as $\mathrm{D}-\mathrm{D}^{\prime}, \mathrm{E}-\mathrm{E}^{\prime}$, and $\mathrm{F}-\mathrm{F}^{\prime}$. The differential strain curve shows a large peak in the D-D' region and a constant value in the $\mathrm{E}^{-\mathrm{E}^{\prime}}$ region. A small hump is observed in region $\mathrm{F}^{\prime}$.

According to a previous report by Ohzuku et al. ${ }^{31}$ the lattice parameter of $\mathrm{LiMn}_{2} \mathrm{O}_{4}$ changes linearly with charge/discharge in the $4 \mathrm{~V}$ range, and there is sudden jump due to a Jahn-Teller effect when it is charged/discharged out of/into the $3 \mathrm{~V}$ range. Therefore, if the spinel electrode is cycled within the $4 \mathrm{~V}$ range, the strain variation should be proportional to the amount of lithium ions inserted or extracted, and the differential strain curve should show a constant value. However, the strain and differential strain curves in Fig. 5 deviate from the expectation of the previous report. As mentioned previously, there is the onset of a Jahn-Teller effect at the end of discharge to consider even in the $4 \mathrm{~V}$ range,,${ }^{12-16}$ and we can predict from this that a drastic strain variation should occur above $3.5 \mathrm{~V}$ during discharge.

The differential strain curve shown in Fig. $5 b$ follows the prediction very well. The large compressive peak in the $\mathrm{D}^{\prime}$ region of the differential strain curve during discharge indicates that a drastic volume expansion occurs that is larger than that in the $\mathrm{B}^{\prime}$ region. The counterpart peak in region $\mathrm{D}^{\prime}$, which occurs during charge, is due to the relaxation of the tetragonal phase, which is formed during the prior period of discharge, into the cubic phase. Due to the repetitive onset and relaxation of the Jahn-Teller effect, some of the active mass may lose its electrical contact with the bulk electrode, and this contributes to the capacity loss. The origin of the small hump in region $\mathrm{F}$ of the differential strain curve is not known, and needs further study.

To investigate the onset and relaxation of the Jahn-Teller effect during cyclic voltammetry, we measured the strain variation during cyclic voltammetry. Figure 6 a shows the strain curve of the second cycle superimposed on the cyclic voltammogram of thin-film $\mathrm{LiMn}_{2} \mathrm{O}_{4}$ measured at a scan rate of $1 \mathrm{mV} / \mathrm{s}$. As in the case of the galvanostatic charge/discharge, tensile strain is experienced during lithium extraction, and compressive strain during lithium insertion. However, the strain curve shown in Fig. 6a shows little hysteresis. As stated above, the strain variation in the $4 \mathrm{~V}$ range should be proportional to the amount of lithium ions inserted/extracted, that is, the differential strain $(d \epsilon / d Q)$ curve should have a constant value, which is the same situation as in the case of galvanostatic charge/ discharge. Figure $6 \mathrm{~b}$ shows the differential strain $(d \epsilon / d Q)$ curve of the second cycle, which is calculated from the data of Fig. 6a. It should be noted that the differential strain $(d \epsilon / d Q)$ curve is very similar to that of the galvanostatic charge/discharge. The differential strain $(d \epsilon / d Q)$ curve in Fig. 6b can also be divided into three regions, which are designated as I-I', II-II' ${ }^{\prime}$ and III-III' ${ }^{\prime}$. During the anodic scan, the differential strain $(d \in / d Q)$ curve shows a positive value, which corresponds to tensile strain, and during the cathodic scan it shows a negative value, which corresponds to compressive strain. In region II-II', the curve shows a constant value and is in agreement with the postulation that is derived from the result of Ohzuku et al.'s report. ${ }^{31}$ However, region I-I', in a similar manner to region $\mathrm{D}-\mathrm{D}^{\prime}$ in Fig. 5b, shows much higher strain than region II-II'. These higher strain values in regions $\mathrm{I}^{\prime}$ and I can also be attributed to the onset and relaxation of the Jahn-Teller effect, respectively. Furthermore, the potentials where the differential strain value in regions $\mathrm{I}^{\prime}$ and $\mathrm{D}^{\prime}$ deviate from the constant value of regions $\mathrm{II}^{\prime}$ and $\mathrm{E}^{\prime}$ are $c a .3 .97$ and $3.99 \mathrm{~V}$, respectively.

From the above results, we can conclude that even in the cyclic voltammetry, a Jahn-Teller effect takes place at the end of the cathodic scan. The onset and relaxation of the Jahn-Teller effect shows up as additional peaks in the differential strain $(d \epsilon / d t)$ curves at potentials around $3.9 \mathrm{~V}$. Figure $6 \mathrm{c}$ shows the differential strain $(d \epsilon / d t)$ curve superimposed on the cyclic voltammogram. Because the lattice parameter change is proportional to the amount of lithium ions inserted/extracted, the strain should be proportional to the charge, and the differential strain $(d \epsilon / d t)$ should be proportional to the current, which is the rate of lithium ion insertion/extraction. Therefore, the differential strain $(d \epsilon / d t)$ curve should have the same shape as the cyclic voltammogram. The differential strain $(d \epsilon / d t)$ curve shows three pairs of peaks which are designated $\alpha-\alpha^{\prime}, \beta-\beta^{\prime}$, and $\gamma-\gamma^{\prime}$. The peaks $\beta-\beta^{\prime}$ are almost buried under the feet of the large peaks $\alpha-\alpha^{\prime}$. The two pairs of peaks $\beta-\beta^{\prime}$ and $\gamma-\gamma^{\prime}$ can be attributed to the two pairs of current peaks in the cyclic voltammogram. However, the peaks $\alpha-\alpha^{\prime}$ cannot be explained by the current peaks in the cyclic voltammogram. From the previous analysis, we can interpret these peaks as corresponding to the onset and relaxation of a Jahn-Teller effect.

If the insertion rate of the lithium ions during discharge or cathodic scan is greater than the diffusion rate of the lithium ions from the surface into the bulk matrix of the $\mathrm{LiMn}_{2} \mathrm{O}_{4}$, there will be an accumulation of lithium ions at the surface of the $\mathrm{LiMn}_{2} \mathrm{O}_{4}$ particles, making the average manganese valence at the surface of the particles fall below 3.5. Therefore, a Jahn-Teller effect is induced, and the cubic phase at the surface of the $\mathrm{LiMn}_{2} \mathrm{O}_{4}$ particles will be transformed into a tetragonal phase. When the cubic phase is transformed into a tetragonal phase, there is a 5.6\% expansion in volume, which is a rather abrupt change compared with the volume expansion due to the lattice parameter change within the cubic phase. ${ }^{31}$ Therefore, this expansion is observed as an additional peak with a large magnitude in the differential strain curves. When the tetragonal phase is formed on the surface of the $\mathrm{LiMn}_{2} \mathrm{O}_{4}$ particles due to the 

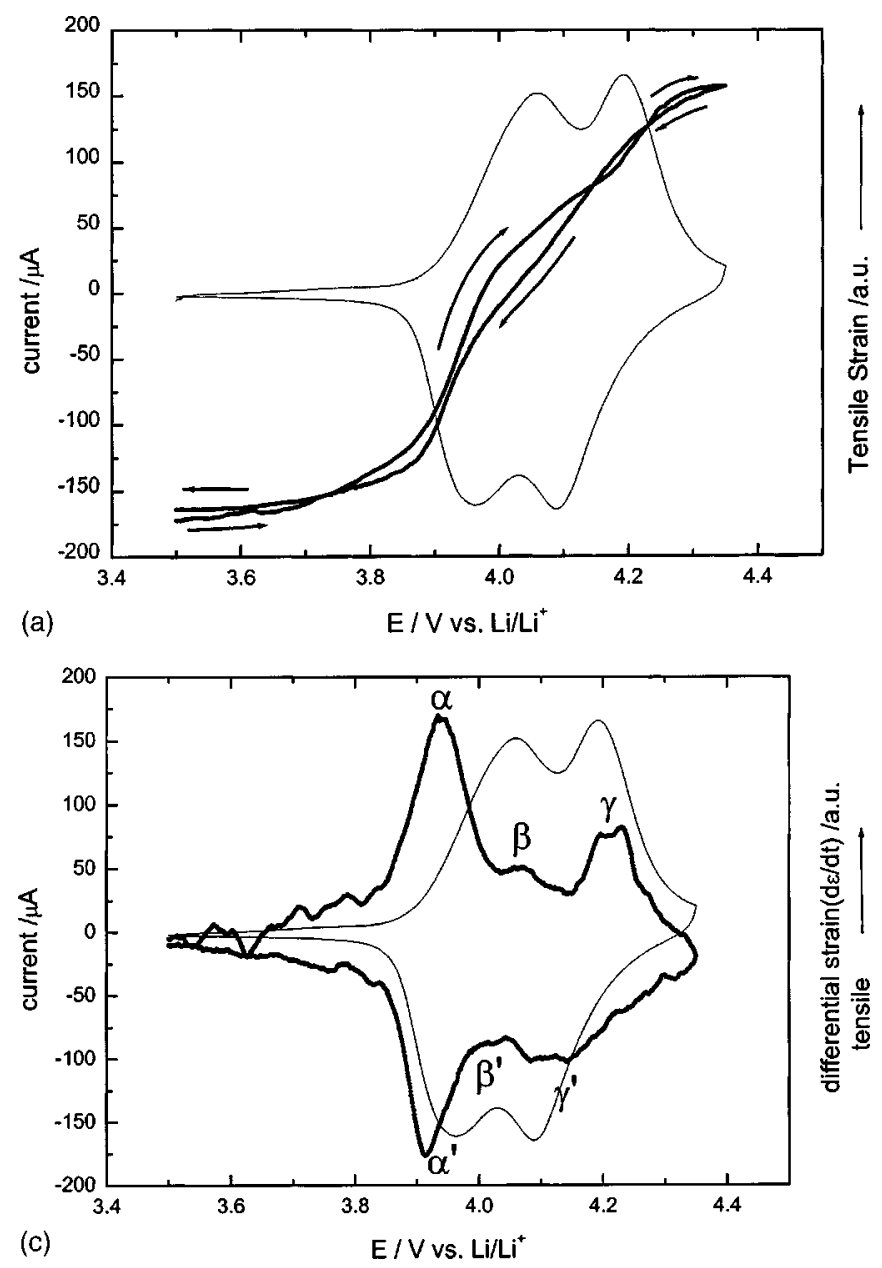

Jahn-Teller effect, there is a misfit between the cubic phase of the bulk and the tetragonal phase at the surface, thus some of the tetragonal phase may dissociate itself from the bulk electrode, and this is what causes the capacity fading.

The substitution of Mn ions with other transition metal ions, which have lower valence than $\mathrm{Mn}$ ions, will increase the average valence of the Mn ions. This gap between the average oxidation states of the Mn ions in the substituted spinel oxide and those in the stoichiometric spinel oxide- $\mathrm{LiMn}_{2} \mathrm{O}_{4}$ acts as a cubic buffer zone that suppresses the onset of the Jahn-Teller effect at the end of discharge or cathodic scan at the surface of the spinel particles. To evaluate the influence of doping on the Jahn-Teller effect, we prepared four sets of transition-metal-ions-substituted spinel oxide, which are $\mathrm{LiCo}_{0.05} \mathrm{Mn}_{1.95} \mathrm{O}_{4}, \quad \mathrm{LiCo}_{0.1} \mathrm{Mn}_{1.9} \mathrm{O}_{4}, \quad \mathrm{LiNi}_{0.05} \mathrm{Mn}_{1.95} \mathrm{O}_{4}, \quad$ and $\mathrm{LiNi}_{0.1} \mathrm{Mn}_{1.95} \mathrm{O}_{4}$. It has previously been reported by several authors that $\mathrm{Co}$ ions resides in the oxidation state of $3+$ and $\mathrm{Ni}$ ions in the oxidation state of $2+$ in spinel oxide. ${ }^{33-35}$ Therefore, when some of the $\mathrm{Mn}$ ions are replaced by other transition metal ions, which are in the oxidation state of $3+$ or $2+$, the average valence of the Mn ions is increased. As the valence of the doping ions decreases or the amount of doping increases, the extent of the cubic buffer zone increases, and the suppression effect becomes more effective.

Figure $7 \mathrm{a}$ and $\mathrm{b}$ show the strain curves of the second cycle superimposed on the cyclic voltammograms of the $\mathrm{LiCo}_{0.05} \mathrm{Mn}_{1.95} \mathrm{O}_{4}$ and $\mathrm{LiNi}_{0.05} \mathrm{Mn}_{1.95} \mathrm{O}_{4}$ thin films, respectively. The cyclic voltammograms and the strain curves in Fig. 7a and b show similar behavior to those in Fig. 6a. However, close examination shows noticeable differences between the cyclic voltammograms and strain curves of Fig. 6a and Fig. 7a and b. The peak shape of the cyclic voltammograms of the doped spinel is broader than that of the stoichiometric spinel, and the peak height decreases as the valence of the dopant

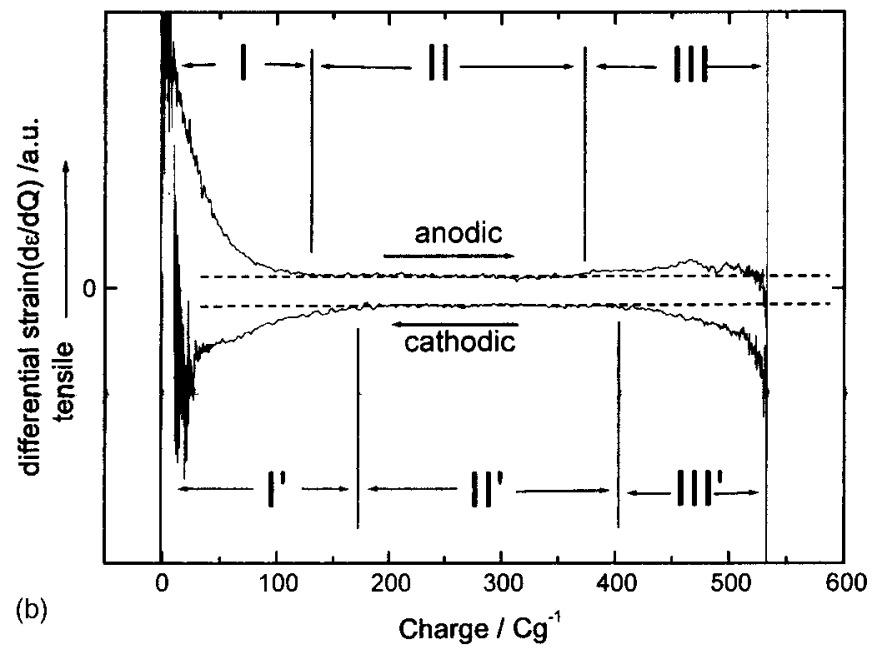

Figure 6. (a) Strain curves (thick line) and differential strain curves, (b) $\mathrm{d} \varepsilon / \mathrm{dQ}$, (c) $d \varepsilon / d t$ (thick line), superimposed on the cyclic voltammograms of thin film $\mathrm{LiMn}_{2} \mathrm{O}_{4}$. Scan rate: $1 \mathrm{mV} / \mathrm{s}$. Cutoff voltage, 3.5-4.35 V. The dashed lines in (b) are the reference lines.

decreases. However, a more important factor to observe is that the slopes of the strain curves at around $3.9 \sim 3.95 \mathrm{~V}$ are different from one another. The slope of the strain curve in Fig. 6a is the steepest among the three, and it becomes less and less steep as one continues from Fig. 7a to Fig. 7b. This can be seen more clearly when the strain curves are differentiated with respect to time.

Figure 8 shows the differential strain curves of the second cycle superimposed on the cyclic voltammetry of $\mathrm{LiM}_{\delta} \mathrm{Mn}_{2-\delta} \mathrm{O}_{4}$. (M $=\mathrm{Co}, \mathrm{Ni} ; \delta=0.05,0.1$; for detailed composition of each figure, see the figure captions.) These differential strain curves are calculated from the strain curves of Fig. 7. (The strain curves of $\mathrm{LiCo}_{0.1} \mathrm{Mn}_{1.9} \mathrm{O}_{4}$ and $\mathrm{LiNi}_{0.1} \mathrm{Mn}_{1.9} \mathrm{O}_{4}$ are not shown in Fig. 7.) As the doping content increases, the peak shape in the cyclic voltammograms becomes broader and the peak height decreases. In previous work, it was reported that the initial capacity of the cathode materials is reduced by doping. ${ }^{33-35}$ When transition metal ions other than $\mathrm{Mn}$ are substituted into the spinel oxide, they reside at the octahedral $16 \mathrm{~d}$ site designated for $\mathrm{Mn}$ ions in the undoped spinel oxide. However, the oxidation state of transition metal ions differs from that of $\mathrm{Mn}$ ions. When Mn ions are substituted with other transition metal ions which have lower valence than $\mathrm{Mn}$ ions, the average oxidation state of the $\mathrm{Mn}$ ions increases, and the amount of $\mathrm{Mn}^{3+}$ decreases. ${ }^{33,35}$ Because only the $\mathrm{Mn}^{3+}$ ions contribute to the charge capacity in the $4 \mathrm{~V}$ range in the case of spinel oxide, the initial charge capacity decreases as the amount of dopant increases. ${ }^{33}$ The cyclic voltammograms in Fig. 8 are in accordance with this postulate, i.e., that the peak height decreases as the content of dopant increases.

In Fig. $8 \mathrm{a}$, it is observed that the peak, $\alpha-\alpha^{\prime}$, is much reduced compared to that of Fig. $6 \mathrm{c}$, with the reduction in the magnitude of 

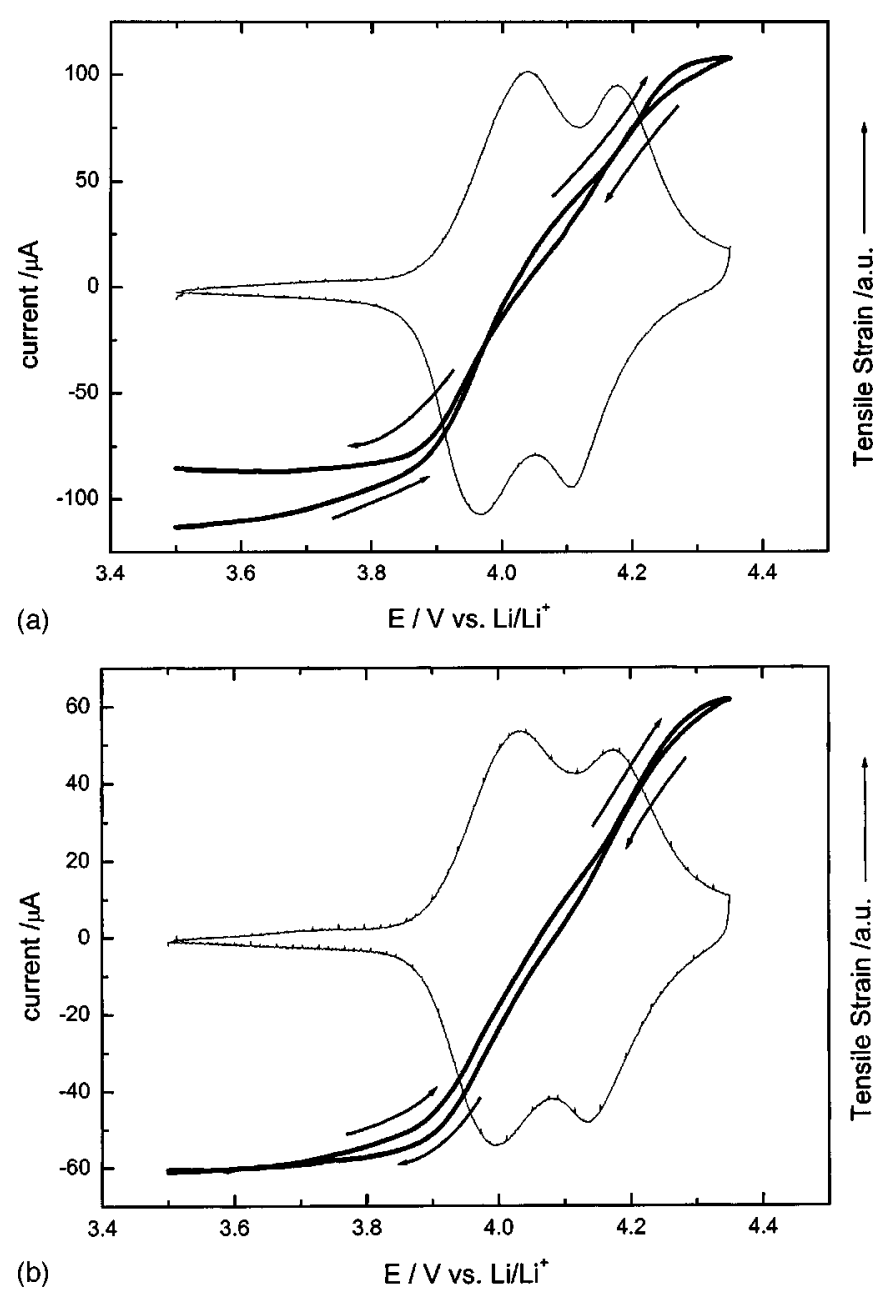

Figure 7. Strain curves (thick line) of superimposed on the cyclic voltammograms (thin line) of thin-film $\mathrm{LiM}_{\delta} \mathrm{Mn}_{2-\delta} \mathrm{O}_{4}$ electrode. (a) $\mathrm{LiCo}_{0.05} \mathrm{Mn}_{1.95} \mathrm{O}_{4}$ and (b) $\mathrm{LiNi}_{0.05} \mathrm{Mn}_{1.95} \mathrm{O}_{4}$. Cutoff voltage: $3.5-4.35 \mathrm{~V}$, scan rate: $1 \mathrm{mV} / \mathrm{s}$.

peak, $\alpha^{\prime}$, being particularly pronounced. Because Mn ions, which have an average oxidation state of 3.5 in the stoichiometric $\mathrm{LiMn}_{2} \mathrm{O}_{4}$, are substituted with lower valence $\mathrm{Co}^{3+}$ ions, the average oxidation state of the $\mathrm{Mn}$ ions increases. In the case of $\mathrm{LiCo}_{0.05} \mathrm{Mn}_{1.95} \mathrm{O}_{4}$, the average oxidation state of the $\mathrm{Mn}$ ions is $c a$. 3.513. As the average oxidation state of the $\mathrm{Mn}$ ions at the end of the cathodic scan in cyclic voltammetry is greater than 3.5 , there is a cubic buffer zone, which prevents the oxidation state of the Mn ions at the surface from falling below 3.5 at the end of the cathodic scan. Therefore, the onset of the Jahn-Teller effect at the end of the cathodic scan in cyclic voltammetry is suppressed. This phenomenon seems to become more distinct when the average oxidation state of the $\mathrm{Mn}$ ions is increased by increasing the doping content of $\mathrm{Co}^{3+}$. Figure $8 \mathrm{~b}$ shows the differential strain curve and cyclic voltammogram of $\mathrm{LiCo}_{0.1} \mathrm{Mn}_{1.9} \mathrm{O}_{4}$. The average oxidation state of $\mathrm{Mn}$ in $\mathrm{LiCo}_{0.1} \mathrm{Mn}_{1.9} \mathrm{O}_{4}$ is 3.526. This value is somewhat larger than that of Fig. 8a, which means that the extent of the cubic buffer zone is increases more and that the Jahn-Teller effect is more effectively suppressed.

The suppression of the Jahn-Teller effect in the $4 \mathrm{~V}$ range is even more pronounced when the valence of the dopant ions is decreased. Figure $8 \mathrm{c}$ and $\mathrm{d}$ show the differential strain curves and cyclic voltammograms of $\mathrm{LiNi}_{0.05} \mathrm{Mn}_{1.95} \mathrm{O}_{4}$ and $\mathrm{LiNi}_{0.1} \mathrm{Mn}_{1.9} \mathrm{O}_{4}$, respectively. It is observed that the magnitude of peak $\alpha^{\prime}$ is substantially decreased compared to that of the $\mathrm{Co}^{3+}$ doped spinels. This is due to the valence of the $\mathrm{Ni}$ ions being lower than that of the Co ions. The oxidation state of the $\mathrm{Ni}$ ions is $2+$, and when the same amount of dopant is substituted into the spinel oxide, the $\mathrm{Ni}$ ions increase the average oxidation state of the $\mathrm{Mn}$ ions more effectively than the Co ions do. The average oxidation states of the $\mathrm{Mn}$ ions in $\mathrm{LiNi}_{0.05} \mathrm{Mn}_{1.95} \mathrm{O}_{4}$ and $\mathrm{LiNi}_{0.1} \mathrm{Mn}_{1.9} \mathrm{O}_{4}$ are 3.538 and 3.579, respectively. These values are greater than those of the Co-doped spinel oxides described in this study. Therefore, there is a larger cubic buffer zone in the Ni-doped spinel oxide than in the $\mathrm{Co}^{3+}$-doped spinel oxide, and so the magnitude of the Jahn-Teller effect in the 4 $\mathrm{V}$ range is lower in the $\mathrm{Ni}^{2+}$-doped spinel oxide. This is observed in Fig. $8 \mathrm{c}$ and d. The magnitude of peak $\alpha^{\prime}$ is much less than that of the peaks in Fig. 8a and b. The differential strain curve in Fig. 8d closely resembles its cyclic voltammogram.

Figure 9 shows the discharge capacity retention of the $\mathrm{LiMn}_{2} \mathrm{O}_{4}$, $\mathrm{LiCo}_{0.05} \mathrm{Mn}_{1.95} \mathrm{O}_{4}$, and $\mathrm{LiNi}_{0.05} \mathrm{Mn}_{1.95} \mathrm{O}_{4}$ thin-film electrodes. The capacity retention is calculated by integrating the cyclic voltammograms against time. It can be seen from Fig. 9 that all three thin-film electrodes prepared by means of the ESD technique show very stable cycling characteristics. From the capacity retention curve in Fig. 9, it can be observed that $\mathrm{LiNi}_{0.05} \mathrm{Mn}_{1.95} \mathrm{O}_{4}$ shows the best capacity retention, followed by $\mathrm{LiCo}_{0.05} \mathrm{Mn}_{1.95} \mathrm{O}_{4}$ and $\mathrm{LiMn}_{2} \mathrm{O}_{4}$. The capacity retentions after 50 cycles are 90.85 and $95.64 \%$ for $\mathrm{LiMn}_{2} \mathrm{O}_{4}$ and $\mathrm{LiCo}_{0.05} \mathrm{Mn}_{1.95} \mathrm{O}_{4}$, respectively. $\mathrm{LiNi}_{0.05} \mathrm{Mn}_{1.95} \mathrm{O}_{4}$ showed almost no capacity loss up to 50 cycles. From the results depicted in Fig. 8a-d, this improvement in cycleability caused by doping is thought to be in large part due to the suppression of the Jahn-Teller effect at around $3.90 \sim 3.95 \mathrm{~V}$.

The suppression of the Jahn-Teller effect at the end of the cathodic scan can also be observed from the same data manipulation as in Fig. 5b. Figure 10a and b show the charge $v s$. differential strain $(d \epsilon / d Q)$ curves of the $\mathrm{LiCo}_{0.05} \mathrm{Mn}_{1.95} \mathrm{O}_{4}$ and $\mathrm{LiNi}_{0.05} \mathrm{Mn}_{1.95} \mathrm{O}_{4}$ thin film electrodes, respectively. The differential strain value is calculated against charge with its sign being changed from a positive to a negative value for the cathodic scan, because the direction of the potential scan is reversed at the potential limit of the anodic scan. The large scattering of the differential strain value at the left side of region $\mathrm{I}^{-\mathrm{I}^{\prime}}$ and at the right side of region III-III' is due to the very small value and small variation of the charge. At both ends of the cyclic voltammogram, i.e., near 3.5 and $4.35 \mathrm{~V}$, the current is very small, and the amount of charge does not change significantly compared to that in the middle region of the cyclic voltammogram, and eventually small scattering in strain will result in a very large scattering in differential strain value calculated with respect to charge.

As for the previous graphs in Fig. 6b and Fig. 8, the differential strain $(d \epsilon / d Q)$ curves in Fig. 10a and b can be divided into three regions, which are designated as I-I', II-II', and III-III' . The region II-II' shows a constant value of differential strain, which indicates that the strain is linearly proportional to the charge. However, regions I-I' and III-III' show some differences from region II-II' . As stated earlier, the larger value of the differential strain $(d \epsilon / d Q)$ in region ${\mathrm{I}-\mathrm{I}^{\prime}}$ is due to the onset and relaxation of the Jahn-Teller effect. The magnitude of the differential strain $(d \epsilon / d Q)$ value in region $I^{\prime}$ decreases as the valence of the dopant decreases. This leads to the same conclusion as that explained in Fig. 8. When the spinel is doped with $\mathrm{Ni}$ ions, it shows almost no deviation from region II-II' . A small hump is observed in region III of the anodic scan. It should be noted that greater compressive differential strain is observed in region $\mathrm{III}^{\prime}$ than in region $\mathrm{II}^{\prime}$ in the cathodic scan. Also, it is observed that the magnitudes of the hump in region III and that of the compressive differential strain in region III' do not change significantly, regardless of the valence of the dopants. The origin of the hump in region III is not yet clear. However, this hump may be related to the dissolution of $\mathrm{Mn}$ ions into the electrolyte, since the potential range of the hump lies approximately in the potential range where the appreciable dissolution of $\mathrm{Mn}$ ions into electrolyte is observed, i.e., $4.0 \sim 4.5 \mathrm{~V} .{ }^{10}$ The larger compressive differential 

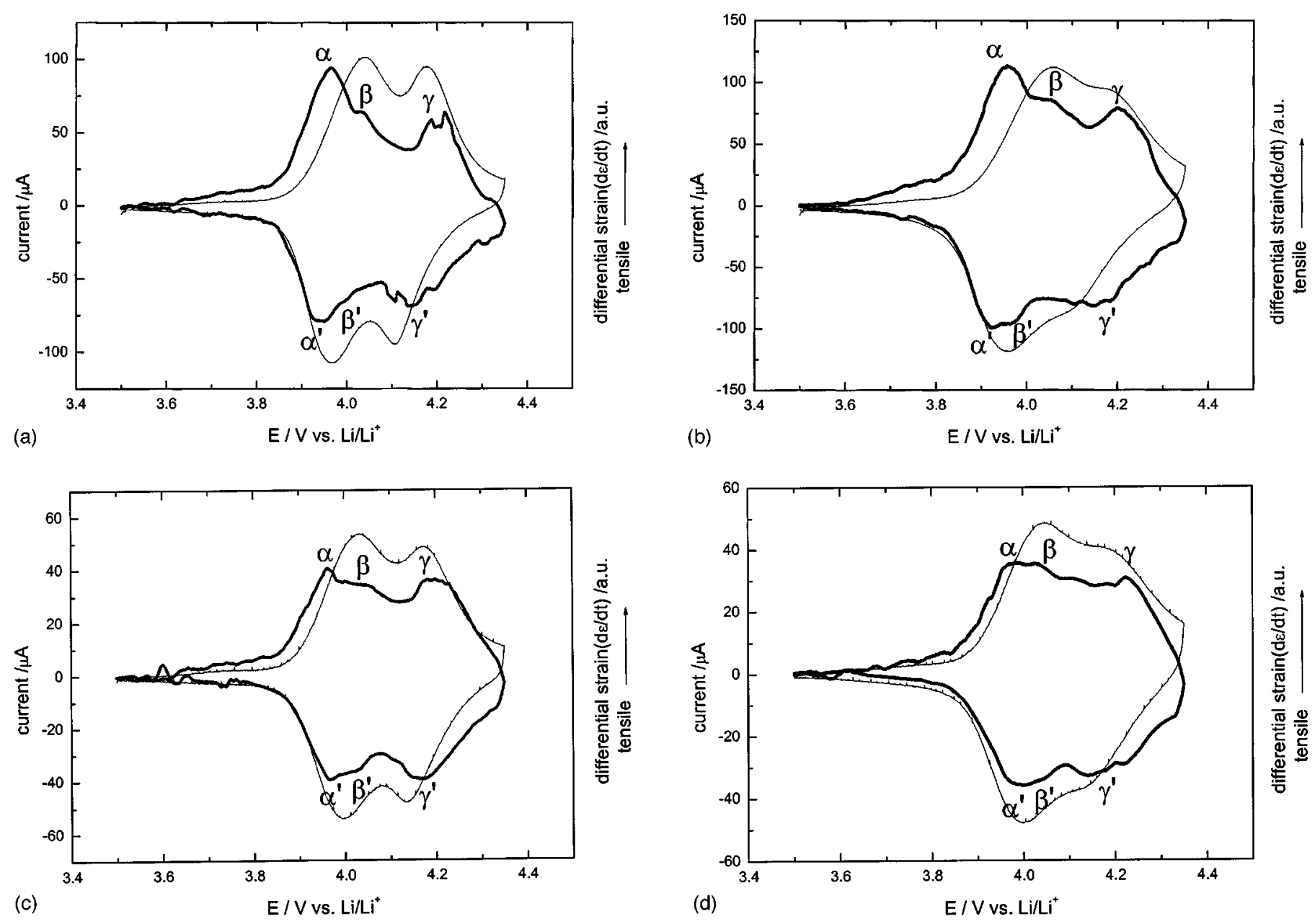

Figure 8. Differential strain curves (thick line) superimposed on the cyclic voltammograms (thin line) of thin film $\operatorname{LiM}_{\delta} \mathrm{Mn}_{2-\delta} \mathrm{O}_{4}:\left(\right.$ a) $\mathrm{LiCo}_{0.05} \mathrm{Mn}_{1.95} \mathrm{O}_{4}(\mathrm{M}$ $=\mathrm{Co}, \delta=0.05) ;\left(\right.$ b) $\mathrm{LiCo}_{0.1} \mathrm{Mn}_{1.9} \mathrm{O}_{4}(\mathrm{M}=\mathrm{Co}, \delta=0.1)$; (c) $\mathrm{LiNi}_{0.05} \mathrm{Mn}_{1.95} \mathrm{O}_{4}(\mathrm{M}=\mathrm{Ni}, \delta=0.05)$; and (d) $\operatorname{LiNi}_{0.1} \mathrm{Mn}_{1.9} \mathrm{O}_{4}(\mathrm{M}=\mathrm{Ni}, \delta=0.1)$. Cutoff voltage: $3.5-4.35 \mathrm{~V}$, Scan rate: $1 \mathrm{mV} / \mathrm{s}$.

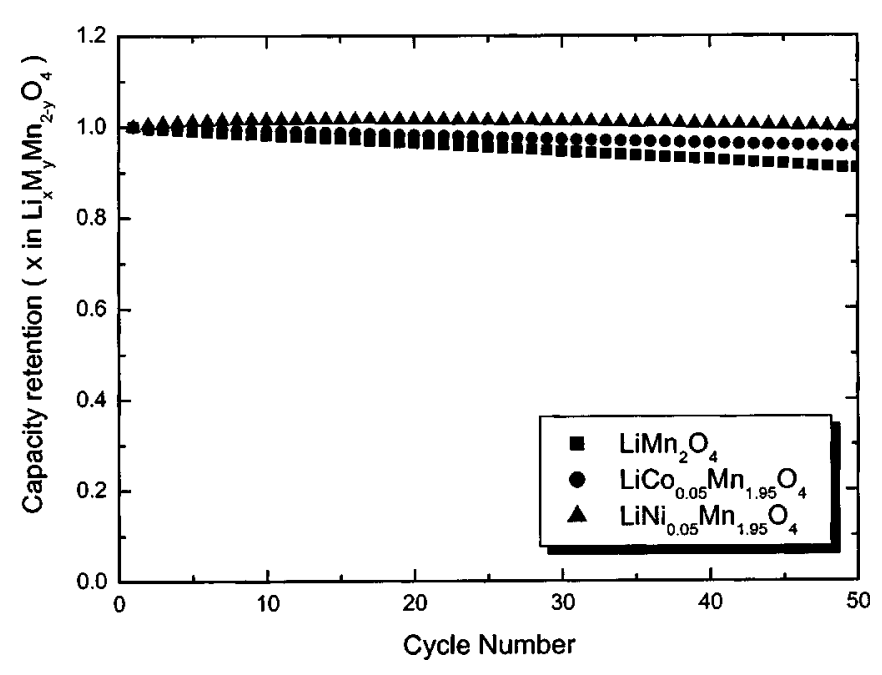

Figure 9. Capacity retention ( $x$ in $\mathrm{Li}_{x} \mathrm{M}_{y} \mathrm{Mn}_{2-y} \mathrm{O}_{4}$ vs. cycle number) calculated from the cyclic voltammogram of $\mathrm{LiMn}_{2} \mathrm{O}_{4}, \mathrm{LiCo}_{0.05} \mathrm{Mn}_{1.95} \mathrm{O}_{4}$, and $\mathrm{LiNi}_{0.05} \mathrm{Mn}_{1.95} \mathrm{O}_{4}$ thin-film electrode. strain in region III' $^{\prime}$ may be attributed to the reversal of the scan directions. Similar phenomena have previously been reported in the case of galvanostatic charge/discharge in $\mathrm{LiMn}_{2} \mathrm{O}_{4}$ thin film electrodes, ${ }^{17}$ and are also to be found in the galvanostatic cycles of electrochromic materials, such as $\mathrm{WO}_{3}$ and $\mathrm{NiO}_{x} \cdot{ }^{36}$ This phenomenon might be related to scan direction reversal. To check the influence of scan direction reversal on the strain curve, we measured the strain over a potential window of 3.96 and $4.185 \mathrm{~V}$, in which region the linearity of the strain against charge is observed in Fig. 5b.

Figure 11a shows the strain curve superimposed on the cyclic voltammogram, and Fig. 11b shows the differential strain $(d \epsilon / d Q)$ curve of the thin film $\mathrm{LiMn}_{2} \mathrm{O}_{4}$ electrode calculated by differentiating the strain curve shown in Fig. 11a with respect to charge. It should be noted that potential cycling was performed between 3.96 and $4.185 \mathrm{~V}$, in which voltage region the strain varies linearly with respect to charge over the entire potential range. The scan rate was set to $1 \mathrm{mV} / \mathrm{s}$. During the anodic scan, tensile strain is developed in the electrode, and during the cathodic scan compressive strain is developed. From Fig. 11b, it can be observed that there is a greater compressive differential strain at the beginning of the cathodic scan and a greater tensile differential strain at the beginning of the anodic scan, compared to the middle region where there is a constant differential strain. Therefore, the greater compressive differential strain at the beginning of the cathodic scan in Fig. 10, region III', may be ascribed to scan direction reversal. The greater tensile differential strain at the beginning of the anodic scan in Fig. 10, region I, com- 

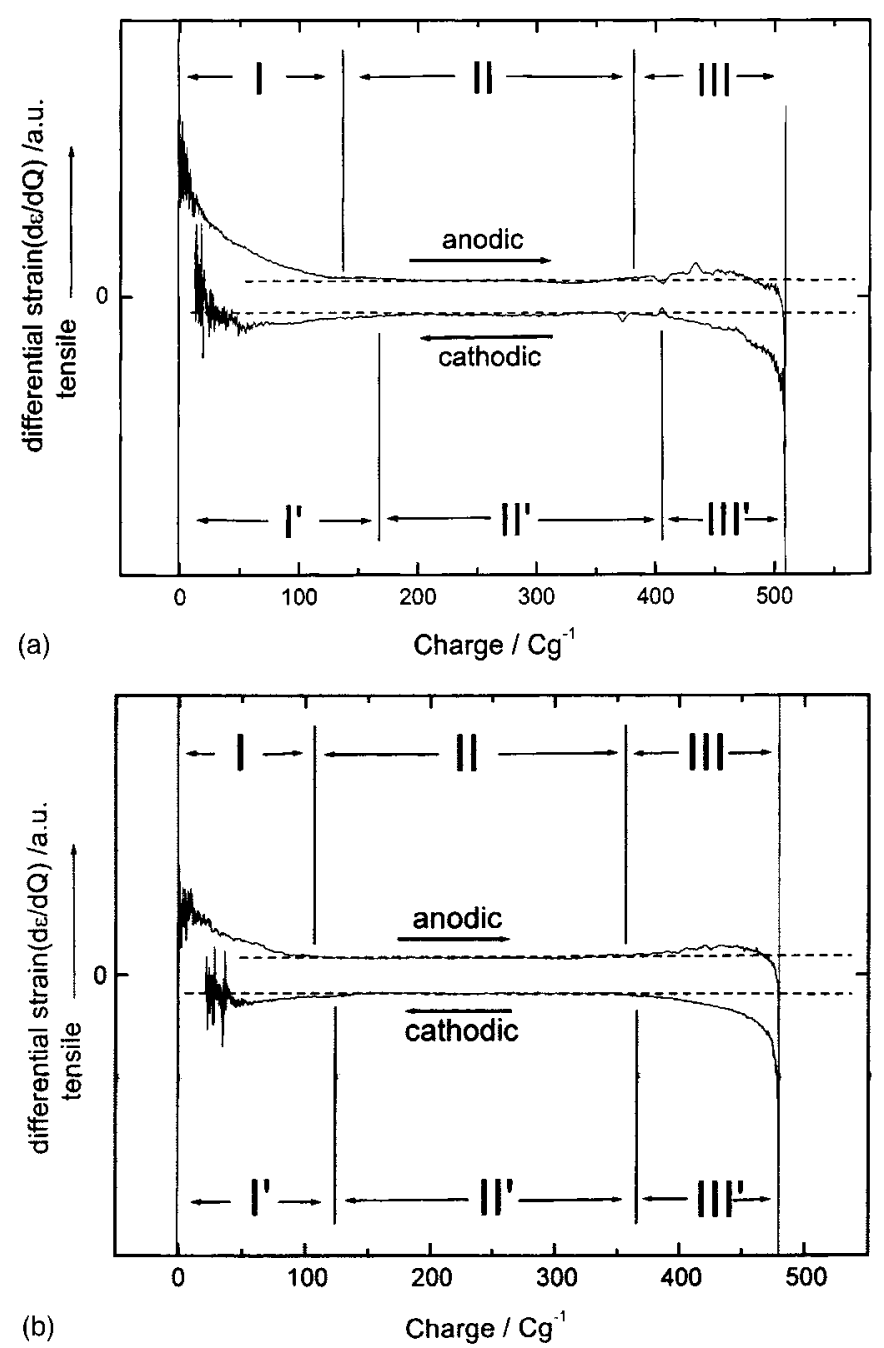

Figure 10. Charge $v s$. differential strain $(d \epsilon / d Q)$ curve of (a) $\mathrm{LiCo}_{0.05} \mathrm{Mn}_{1.95} \mathrm{O}_{4}$ and (b) $\mathrm{LiNi}_{0.05} \mathrm{Mn}_{1.95} \mathrm{O}_{4}$ thin film electrode. The dashed lines are reference lines.

pared to the end of the cathodic scan-region I may also be in some part ascribed to scan direction reversal.

\section{Conclusions}

Evidence of the onset of the Jahn-Teller effect in thin-film $\mathrm{LiMn}_{2} \mathrm{O}_{4}$ and for the suppression of the Jahn-Teller effect caused by the substitution of $\mathrm{Mn}$ ions with other transition metal ions $\left(\mathrm{Co}^{3+}\right.$ and $\mathrm{Ni}^{2+}$ ) during cyclic voltammetry in the $4 \mathrm{~V}$ range was obtained by means of in situ BBM. The thin-film $\mathrm{LiM}_{\delta} \mathrm{Mn}_{2-\delta} \mathrm{O}_{4}$ (M $=\mathrm{Co}^{3+}$ and $\mathrm{Ni}^{2+} ; \delta=0,0.05$, and 0.1$)$ electrodes were prepared by the ESD technique. The strain data were obtained simultaneously during cyclic voltammetry, and the differential strain curves were analyzed in conjunction with electrochemical data to examine the onset and suppression of the Jahn-Teller effect in thin-film $\mathrm{LiM}_{\delta} \mathrm{Mn}_{2-\delta} \mathrm{O}_{4}$ electrodes in the $4 \mathrm{~V}$ range.

The onset of the Jahn-Teller effect is detected at around 3.90$3.95 \mathrm{~V}$ by the occurrence of additional peaks which are not related to the current peaks in the cyclic voltammograms. This is due to the accumulation of lithium ions at the surface of the $\mathrm{LiMn}_{2} \mathrm{O}_{4}$ particles during the cathodic scan in nonequilibrium, dynamic conditions.

The suppression of the Jahn-Teller effect caused by substituting the Mn ions with other transition metal ions is observed by means of the variation in the magnitude of the additional peaks. The magnitude of this additional peak decreased when the spinel oxide was
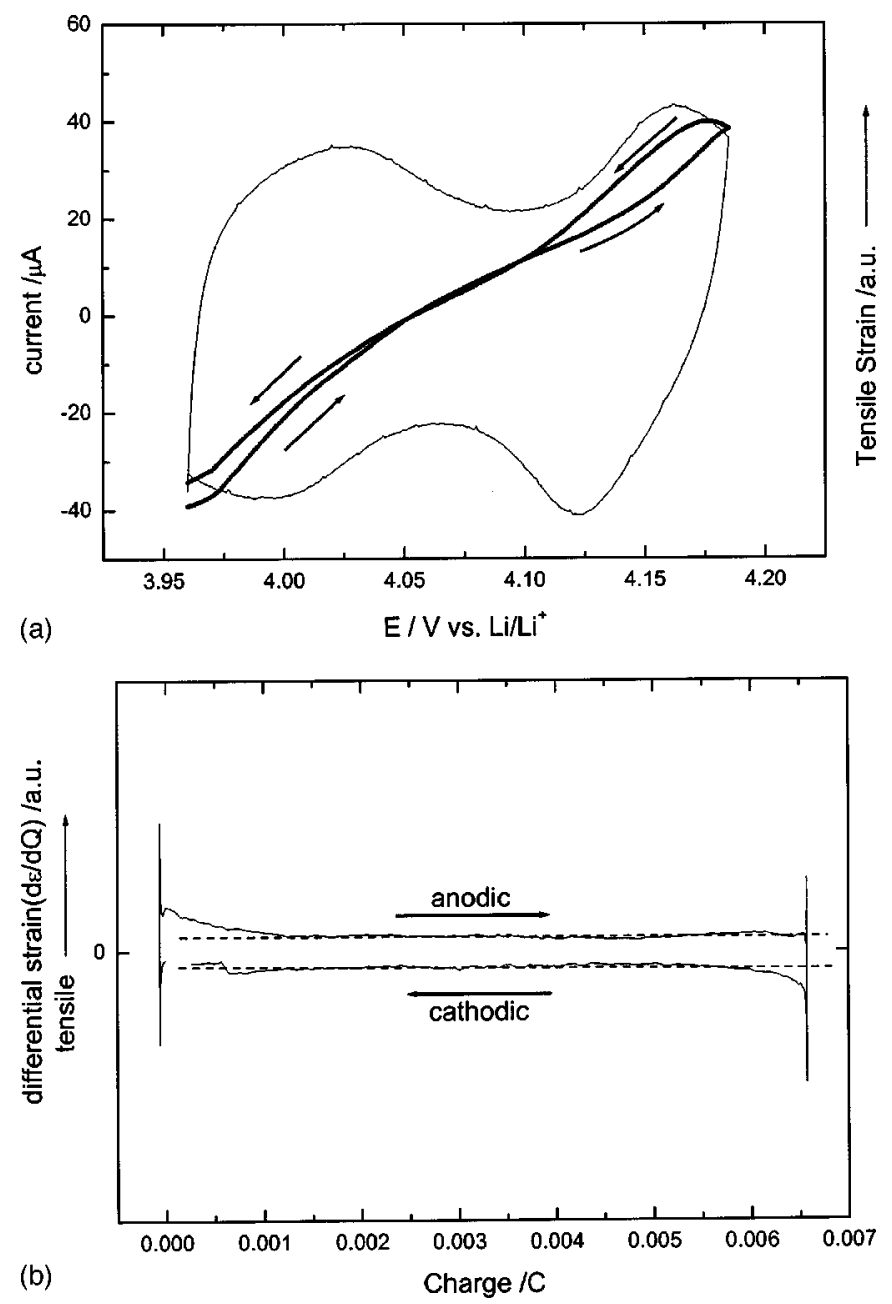

Figure 11. (a) Strain curves (thick line) of superimposed on the cyclic voltammograms (thin line) and (b) charge vs. differential strain $(d \epsilon / d Q)$ curve of thin-film $\mathrm{LiMn}_{2} \mathrm{O}_{4}$ electrode. The dashed lines in (b) are reference lines. Cutoff voltage: $3.96-4.185 \mathrm{~V}$; scan rate; $1 \mathrm{mV} / \mathrm{s}$.

doped with metal ions having a lower valence than $\mathrm{Mn}$ ions. As expected from the differential strain curves, the $\mathrm{Ni}^{2+}$ substituted spinel showed the best cycleability with little capacity fading up to the 50th cycle.

From the differential $(d \epsilon / d Q)$ strain curves, we were able to obtain clearer evidence for the existence of a Jahn-Teller effect along with some other important information. The onset and suppression of the Jahn-Teller effect was probed by means of the decrease in the differential strain value $(d \epsilon / d Q)$ near the lower end of the potential window. The onset of this effect is a rather progressive process compared to its subsequent relaxation, and this is revealed by the width and magnitude of the region responsible for the JahnTeller effect in the differential strain $(d \epsilon / d Q)$ strain curves.

In situ BBM proved to be a very powerful technique for measuring very small variations in strain during electrochemical experiments, thus providing information about phase transformations at the surface of the spinel thin film electrode.

\section{Acknowledgments}

This work was supported by KOSEF through the Research Center for Energy Conversion and Storage (RCECS), Korea Science and Engineering Foundation (no. 2000-2-30100-012-3) and by the Ministry of Information and Communication of Korea (Support Project 
of University Information Technology Research Center supervised by KIPA). The authors thank Cheil Industries, Inc., for the supporting electrolytes.

Yonsei University assisted in meeting the publication costs of this article.

\section{References}

1. K. Mizushima, P. C. Jones, P. C. Wiseman, and J. B. Goodenough, Mater. Res. Bull., 15, 783 (1980).

2. W.-S. Yoon, K.-K. Lee, and K.-B. Kim, J. Electrochem. Soc., 147, 2023 (2000).

3. W.-S. Yoon, K.-K. Lee, and K.-B. Kim, Electrochem. Solid-State Lett., 4, A35 (2001).

4. W.-S. Yoon, K.-K. Lee, and K.-B. Kim, J. Electrochem. Soc., 149, A146 (2002).

5. M. G. S. R. Thomas, W. I. F. David, J. B. Goodenough, and P. Groves, Mater. Res. Bull., 20, 1137 (1985).

6. K.-K. Lee and K.-B. Kim, J. Electrochem. Soc., 147, 1709 (2000).

7. K.-K. Lee, W.-S. Yoon, K.-B. Kim, K.-Y. Lee, and S.-T. Hong, J. Electrochem Soc., 148, A716 (2001).

8. K.-K. Lee, W.-S. Yoon, and K.-B. Kim, J. Electrochem. Soc., 148, A1164 (2001)

9. M. M. Thackeray, Prog. Solid State Chem., 25, 1 (1997).

10. D. H. Jang, Y. J. Shin, and S. M. Oh, J. Electrochem. Soc., 143, 2204 (1996)

11. Y. Xia and M. Yoshio, J. Power Sources, 66, 129 (1997).

12. R. J. Gummow, A. de Kock, and M. M. Thackeray, Solid State Ionics, 69, 59 (1994).

13. M. M. Thackeray, J. Electrochem. Soc., 142, 2558 (1995).

14. M. M. Thackeray, Y. Shao-Horn, A. J. Kahaian, K. D. Kelper, E. Skinner, J. T. Vaughey, and S. A. Hackney, Electrochem. Solid-State Lett., 1, 7 (1998).

15. M. M. Thackeray, C. S. Johnson, A. J. Kahaian, K. D. Kelper, J. T. Vaughey, Y. Shao-Horn, and S. A. Hackney, J. Power Sources, 81-82, 60 (1999).
16. Y. Shao-Horn, S. A. Hackney, A. J. Kahaian, K. D. Kepler, E. Skinner, J. T. Vaughney, and M. M. Thackeray, J. Power Sources, 81-82, 496 (1999).

17. K. Y. Chung and K.-B. Kim, J. Electrochem. Soc., 149, A79 (2002).

18. M.-R. Lim, W.-I. Cho, and K.-B. Kim, J. Power Sources, 92, 168 (2001).

19. A. A. van Zomeren, E. M. Kelder, J. C. M. Marijnissen, and J. Shoonman, J. Aerosol Sci., 25, 1229 (1994).

20. C. Chen, E. M. Kelder, and J. Shoonman, J. Electrochem. Soc., 144, L289 (1997).

21. M. Nishizawa, T. Uchiyama, K. Dokko, K. Yamada, T. Matsue, and I. Uchida, Bull. Soc. Chim. Fr., 71, 2011 (1998)

22. M. Nishizawa, T. Uchiyama, T. Itoh, T. Abe, and I. Uchida, Langmuir, 15, 4949 (1999).

23. T. Uchiyama, M. Nishizawa, T. Itoh, and I. Uchida, J. Electrochem. Soc., 147, 2057 (2000).

24. W. S. Yoon, S. H. Ban, K. K. Lee, K. B. Kim, M. G. Kim, and J. M. Lee, J. Power Sources, 97-98, $282(2001)$

25. K.-W. Nam and K.-B. Kim, Electrochemistry (Tokyo, Jpn.), 69, 467 (2001).

26. I.-H. Kim and K.-B. Kim, Electrochem. Solid-State Lett., 4, A62 (2001).

27. G. G. Stoney, Proc. R. Soc. London, A82, 172 (1909).

28. J. M. Rosolen and F. Decker, J. Electrochem. Soc., 143, 2417 (1996)

29. C. A. Klein, J. Appl. Phys., 88, 5487 (2000).

30. A. V. Dobrynin, Tech. Phys. Lett., 23, 709 (1997).

31. T. Ohzuku, M. Kitagawa, and T. Hirai, J. Electrochem. Soc., 137, 769 (1990).

32. K. Miura, A. Yamada, and M. Tanaka, Electrochim. Acta, 41, 249 (1996).

33. L. Guohia, H. Ikuta, T. Uchida, and M. Wakihara, J. Electrochem. Soc., 143, 178 (1996).

34. Y. M. Todorov, Y. Hideshima, H. Noguchi, and M. Yoshio, J. Power Sources, 77, 198 (1999).

35. M. Okada, Y. S. Lee, and M. Yoshio, J. Power Sources, 90, 196 (2000).

36. F. Decker, R. Pileggi, S. Passerini, and B. Scrosati, J. Electrochem. Soc., 138, 3182 (1991). 